\title{
Global distribution of vertical wavenumber spectra in the lower stratosphere observed using high-vertical-resolution temperature profiles from COSMIC GPS radio occultation
}

\author{
Noersomadi $^{1}$ and T. Tsuda ${ }^{2}$ \\ ${ }^{1}$ Center of Atmospheric Science and Technology, National Institute of Aeronautics \\ and Space (LAPAN), Bandung, Indonesia \\ ${ }^{2}$ Research Institute for Sustainable Humanosphere (RISH), Kyoto University, Kyoto, Japan \\ Correspondence to: Noersomadi (noersomadi@lapan.go.id)
}

Received: 8 September 2015 - Revised: 15 December 2015 - Accepted: 15 January 2016 - Published: 10 February 2016

\begin{abstract}
We retrieved temperature ( $T$ ) profiles with a high vertical resolution using the full spectrum inversion (FSI) method from the Constellation Observing System for Meteorology, Ionosphere and Climate (COSMIC) GPS radio occultation (GPS-RO) data from January 2007 to December 2009. We studied the characteristics of temperature perturbations in the stratosphere at $20-27 \mathrm{~km}$ altitude. This height range does not include a sharp jump in the background Brunt-Väisälä frequency squared $\left(N^{2}\right)$ near the tropopause, and it was reasonably stable regardless of season and latitude. We analyzed the vertical wavenumber spectra of gravity waves (GWs) with vertical wavelengths ranging from 0.5 to $3.5 \mathrm{~km}$, and we integrated the (total) potential energy $E_{\mathrm{p}}^{\mathrm{T}}$. Another integration of the spectra from 0.5 to $1.75 \mathrm{~km}$ was defined as $E_{\mathrm{p}}^{\mathrm{S}}$ for short vertical wavelength GWs, which was not studied with the conventional geometrical optics (GO) retrievals. We also estimated the logarithmic spectral slope $(p)$ for the saturated portion of spectra with a linear regression fitting from 0.5 to $1.75 \mathrm{~km}$.

Latitude and time variations in the spectral parameters were investigated in two longitudinal regions: (a) $90-150^{\circ} \mathrm{E}$, where the topography was more complicated, and (b) 170 $230^{\circ} \mathrm{E}$, which is dominated by oceans. We compared $E_{\mathrm{p}}^{\mathrm{T}}$, $E_{\mathrm{p}}^{\mathrm{S}}$, and $p$, with the mean zonal winds $(U)$ and outgoing longwave radiation (OLR). We also show a ratio of $E_{\mathrm{p}}^{\mathrm{S}}$ to $E_{\mathrm{p}}^{\mathrm{T}}$ and discuss the generation source of $E_{\mathrm{p}}^{\mathrm{S}} \cdot E_{\mathrm{p}}^{\mathrm{T}}$ and $p$ clearly showed an annual cycle, with their maximum values in winter at $30-50^{\circ} \mathrm{N}$ in region (a), and $50-70^{\circ} \mathrm{N}$ in region (b), which was related to the topography. At $30-50^{\circ} \mathrm{N}$ in region (b), $E_{\mathrm{p}}^{\mathrm{T}}$ and $p$ exhibited some irregular variations in ad-
\end{abstract}

dition to an annual cycle. In the Southern Hemisphere, we also found an annual oscillation in $E_{\mathrm{p}}^{\mathrm{T}}$ and $p$, but it showed a time lag of about 2 months relative to $U$. Characteristics of $E_{\mathrm{p}}^{\mathrm{T}}$ and $p$ in the tropical region seem to be related to convective activity. The ratio of $E_{\mathrm{p}}^{\mathrm{T}}$ to the theoretical model value, assuming saturated GWs, became larger in the equatorial region and over mountainous regions.

Keywords. Meteorology and atmospheric dynamics (waves and tides)

\section{Introduction}

Atmospheric gravity waves (GWs) play an important role in driving the general circulation of the middle atmosphere, transporting momentum flux, and kinetic energy from the lower atmosphere to the stratosphere and mesosphere (e.g. Fritts and Alexander, 2003; Alexander et al., 2010). The fundamental mechanism of GWs, as well as seasonal variations in GW activity, have been studied with groundbased measurements, such as mesosphere-stratospheretroposphere (MST) radars (e.g. Babu et al., 2008; Tsuda, 2014), Rayleigh lidars (Yamashita et al., 2009; Alexander et al., 2011), rockets (Eckermann et al., 1995), and radiosondes (Tsuda et al., 1991; Zhang et al., 2006). Satellite observations have revealed a global distribution of GW activity in the middle atmosphere (Wu and Waters, 1996; Tsuda et al., 2000; de la Torre and Alexander, 2005; Jiang et al., 2005). Numerical model experiments of the global circulation have showed the 
behavior of GWs (Alexander et al., 2002; Kawatani et al., 2009; Sato et al., 2012).

There are various generation mechanisms of GWs, such as tropical convection, orographic generation (topography), and wave-wave interactions, where their importance depends on latitude, altitude, and season (e.g. Fritts, 1989; Fritts and Alexander, 2003). Murayama et al. (1994) reported a clear correlation between GW activity and the magnitude of subtropical jet streams using Middle and Upper Atmosphere Radar (MU) observations. Orographic generation of GWs has previously been observed with balloon soundings and satellite measurements over the Andes (Alexander et al., 2008a) and Antarctica (Baumgaertner and McDonald, 2007; Sato and Yoshiki, 2008). Effects of the polar night jet and sudden stratospheric warming events on GW excitation have also been studied (Yoshiki et al., 2004; Hei et al., 2008).

Monochromatic GWs are sometimes observed in temperature and wind velocity profiles (Eckermann, 1995), but more often, perturbations generally appear as superposition of many GWs. Therefore, the characteristics of GWs can be investigated using spectral analyses in terms of frequency and horizontal and vertical wavenumbers. VanZandt (1982) surveyed available results of GW spectra and proposed a universal spectrum of GWs that agrees well with observed spectra. In particular, the vertical wavenumber spectrum was explained by a saturated GW model (Smith et al., 1987), assuming that the dissipation of GWs is due to convective instability (Lindzen, 1981). This model was verified by comparing the observations with MST radars (e.g. Fritts and Chou, 1987; Tsuda et al., 1989; Eckermann, 1995) and radiosondes (e.g., Tsuda et al., 1991). Seasonal and latitudinal variations in vertical wavenumber spectra have also been explained using a simple model (Alexander et al., 2002). Complete vertical wavenumber spectra can be analyzed well using radiosonde observations (e.g. Wu et al., 2006; Zhang et al., 2006). However, routine radiosonde soundings are mostly limited to specific locations over land at middle latitudes in the Northern Hemisphere (NH).

GPS radio occultation (GPS-RO) is characterized by a very high vertical resolution, superior to other satellite radiometer techniques (Kursinski et al., 1997; Rocken, 1997), and it is used to study the mesoscale perturbations caused by GWs. Latitude variations in the vertical wavenumber spectra of GW have been studied using GPS-RO temperature profiles with the GPS/Met and CHAMP satellites (Tsuda and Hocke, 2002; Ratnam et al., 2004). Note that these profiles were retrieved using the geometrical optics (GO) method, whose vertical resolution is limited to approximately $1.4 \mathrm{~km}$ by a Fresnel zone. Marquardt and Healy (2005) and Wu (2006) discussed measurement error and height resolution of GPSRO profiles by using a conventional GO retrieval. Small vertical scale fluctuations are smoothed out in the GO retrieval; therefore, the results do not clarify the activity of GWs with vertical wavelengths shorter than about $2 \mathrm{~km}$. Šácha et al. (2014) employed the GPS-RO density profiles for GW analysis and discussed the advantages for GW analysis of appropriately removing the background component from a snapshot profile.

This research describes global distributions of vertical wavenumber spectra of temperature profiles derived using the full spectrum inversion (FSI) retrieval method (Jensen et al., 2003). We used the GPS-RO temperature data obtained by the Constellation Observing System for Meteorology, Ionosphere and Climate (COSMIC) mission (Kuo et al., 2004). The COSMIC Data Analysis Archive Center/CDAAC (CDAAC - www.cosmic.ucar.edu) at the University Corporation for Atmospheric Research (UCAR) published the temperature profiles using two basic inversion algorithms of GPS-RO: GO and FSI. At the CDAAC, the FSI technique is applied to only layers below the middle troposphere (Kuo et al., 2004). Tsuda et al. (2011) applied an FSI retrieval in the stratosphere up to about $30 \mathrm{~km}$ altitude, and investigated spectra for wavelengths as short as $0.5 \mathrm{~km}$.

The present study is an extension of Tsuda et al. (2011), and we aimed at studying the global distribution of vertical wavenumber spectra by applying FSI retrieval in the lower stratosphere using COSMIC GPS-RO data. We focused on latitude variations in the vertical wavenumber spectra, concentrating on their relation with the topography and background mean zonal winds.

In Sect. 2 we briefly explain the procedure of the analysis of vertical wavenumber spectra of normalized temperature fluctuations. A description of an analysis of the latitudetime and altitude-latitude distributions of the Brunt-Väisälä frequency squared $\left(N^{2}\right)$ is provided in Sect. 3, followed by an investigation on the latitude-time variation in GW potential energy, logarithmic spectral slope, topography, and zonal winds. We calculated statistical results of standard score $(z$ score) (Wu et al., 2001) to analyze the relationship between these variables by assuming that their variance followed the Gaussian distribution. We also investigated the ratio of the observed GW potential energy and the model prediction by the saturated gravity wave theory (Smith et al., 1987).

\section{Data analyses}

Figure 1 shows a global topographic map with a $0.25^{\circ} \times 0.25^{\circ}$ resolution provided by the National Geophysical Data Center. It is reported that the topography over the Tibetan Plateau, Rocky Mountains, and Andes contributes to the generation of GWs (e.g. Alexander et al., 2008a). In the tropics, GWs are emitted by convective clouds (Tsuda et al., 2009). Interactions with the stratospheric quasi-biennial oscillation (QBO) were investigated using a numerical model (Alexander and Holton, 1997; Kawatani et al., 2009), which was verified through observations (Randel and $\mathrm{Wu}, 2005$; Alexander et al., 2008b). In addition, wind shear can also be a dominant mechanism for the generation of GWs (Fritts and Alexander, 2003). 


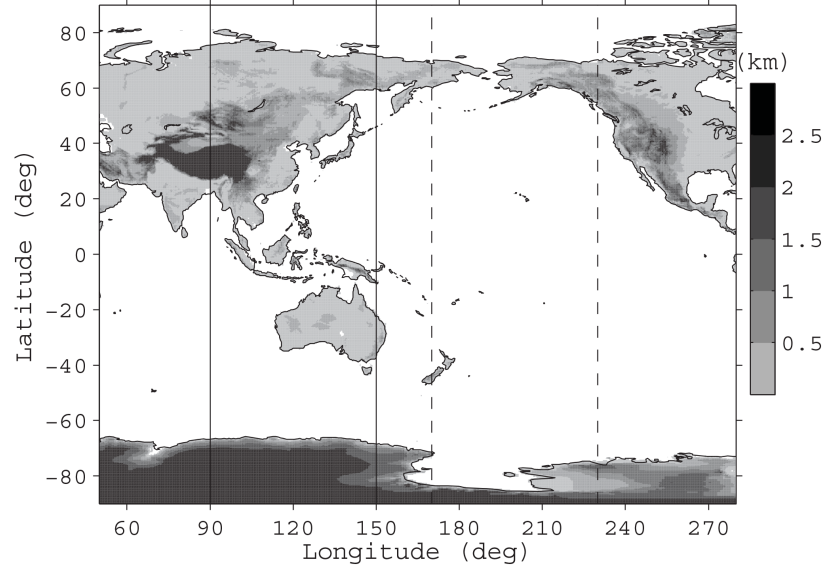

Figure 1. Global topography map with a $0.25^{\circ} \times 0.25^{\circ}$ resolution taken from National Geophysical Data Center (www.ngdc.noaa. gov). Solid and dashed lines delimit the longitude regions (a) 90$150^{\circ} \mathrm{E}$ and (b) $170-230^{\circ} \mathrm{E}$, respectively.

In this study, considering these generation sources of GWs, two different longitude regions were selected to elaborate characteristics of vertical wavenumber spectra from COSMIC GPS-RO data. Figure 1 shows two longitude regions: (a) $90-150^{\circ} \mathrm{E}$ and (b) $170-230^{\circ} \mathrm{E}$. The former includes Asia, Australia, and hills of Antarctica, while the latter is dominated by ocean and does not include much topography except at $50-70^{\circ} \mathrm{N}$ and the northern part of New Zealand.

Individual profiles of temperature $(T)$ retrieved with the FSI method from COSMIC GPS-RO data were sorted with a height interval of $100 \mathrm{~m}$, consisting of the background mean temperature $T_{0}$ and perturbation components $T^{\prime}\left(T^{\prime}=\right.$ $T-T_{0}$ ). Figure 2 shows a comparison between the $T$ profile retrieved with the GO method at the CDAAC and that using our method. In general, these profiles are consistent, but the FSI result exhibits waves with smaller vertical scales. We estimated $T_{0}$ as a linear profile at $20-27 \mathrm{~km}$ altitude, applying a least-squares fitting. For analyzing small-scale temperature fluctuations with vertical wavelengths as short as $0.5 \mathrm{~km}$, Tsuda et al. (2011) reported that the upper limit of the FSI profiles is about $28 \mathrm{~km}$. Therefore, we selected the height range of $20-27 \mathrm{~km}$ for analyzing the GW spectrum. The bottom height $(20 \mathrm{~km})$ was determined by investigating the height of the tropopause as well as latitude-height distribution of atmospheric stability as discussed in a later section (Sect. 3.1).

The saturated spectrum of normalized temperature perturbations $\frac{T^{\prime}}{T_{0}}$ can be expressed as a function of the vertical wavenumber $m$ as

$$
F_{\frac{T^{\prime}}{T_{0}}}=\frac{N^{4}}{10 \mathrm{~g}^{2} \mathrm{~m}^{-3}}
$$
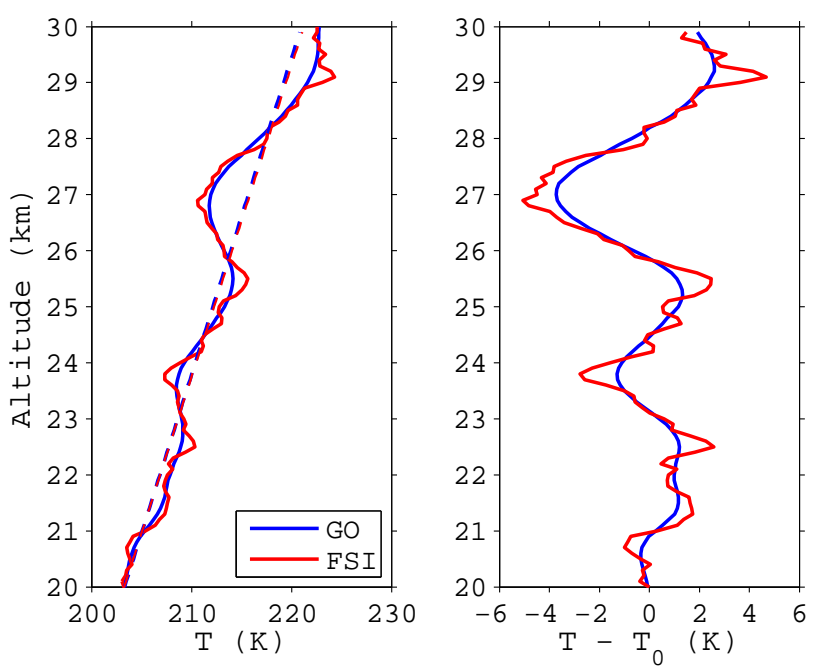

Figure 2. Atmospheric temperature profiles retrieved by GO (blue line) and FSI (red line) methods from COSMIC GPS-RO data obtained at 00:03 UTC on 1 January 2007 at $1.31^{\circ} \mathrm{N}$ and $136.265^{\circ} \mathrm{E}$. The GO profile is obtained from CDAAC. Left panel shows the original temperature profiles with a linear fitting in dashed line. Right panel shows perturbation components (replotted from Tsuda et al., 2011).

where the unit for wavenumber is cycles per meter $\left(\right.$ cyc m$\left.{ }^{-1}\right) . g$ and $N^{2}$ are gravitational acceleration and the Brunt-Väisälä frequency squared, respectively. We calculated $F_{\frac{T^{\prime}}{T_{0}}}(m)$ following the analysis procedure in Tsuda et al. (2011). A linear trend of $T$ was subtracted before multiplying the Hanning window function. Then, a fast Fourier transform was applied. Figure 3 shows an example of the spectrum from the temperature profiles shown in Fig. 2. The top panels are plotted in a common format with $F(m)$ and $\log (m)$ as the vertical and horizontal axes, respectively. The bottom panels are a so-called area-preserving plot of spectra (Fritts et al., 1988), showing $m F(m)$ on the vertical axis with a linear scale. Note that the integrated area beneath the areapreserving spectrum in a specific wavenumber range from $m_{1}$ to $m_{2}$ becomes equal to the integrated potential energy,

$E_{\mathrm{p}}=C \int_{m_{1}}^{m_{2}} m F(m) d(\log m)=C \int_{m_{1}}^{m_{2}} F(m) \mathrm{d} m$,

where $C=\frac{1}{2} \frac{g^{2}}{N^{2}}$. In the top panels in Fig. 3, we also show a theoretical model spectrum from Eq. (1). It is clear that the GO retrievals do not resolve perturbations with $m$ larger than about $6 \times 10^{-4} \mathrm{cyc} \mathrm{m}^{-1}$, corresponding to a vertical wavelength of $1.75 \mathrm{~km}$. FSI results agree with the model in Eq. (1) down to $m=5 \times 10^{-3} \mathrm{cyc} \mathrm{m}^{-1}$, i.e., $200 \mathrm{~m}$ in wavelength. The bottom panels indicate that the integrated energy is underestimated in the GO results even for a small $m$. Figure 3 shows the advantage of the FSI method for studying GW 


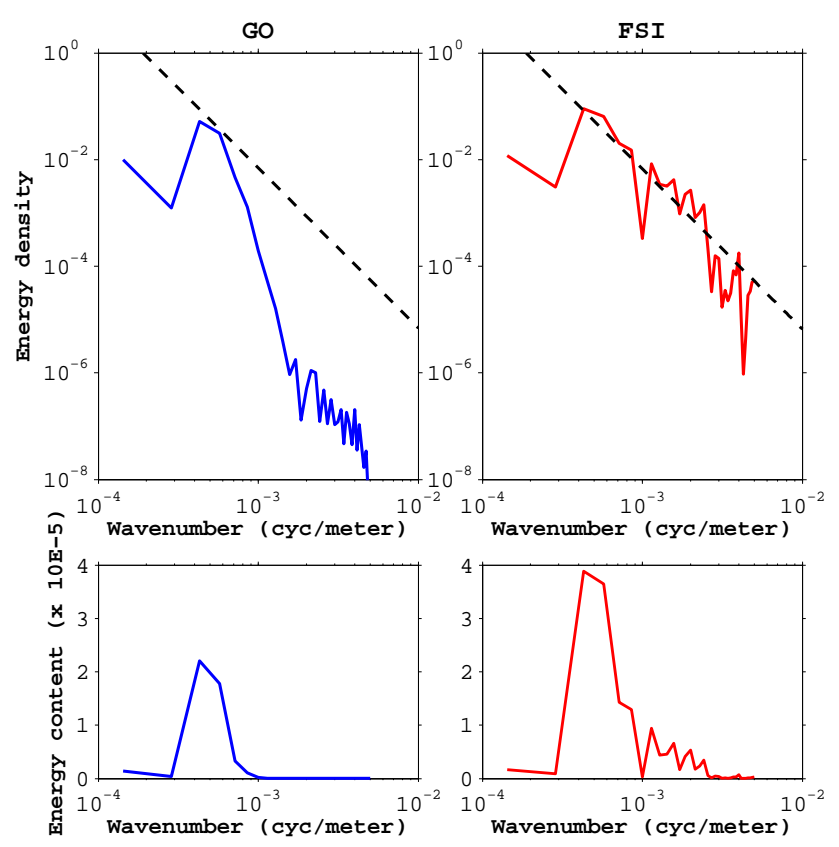

Figure 3. Vertical wavenumber spectra of the normalized temperature $T^{\prime} / T_{0}$ profiles shown in Fig. 2 at $20-27 \mathrm{~km}$ height range. A model spectrum of saturated gravity waves from Eq. (1) is plotted as a dashed line. Bottom panels show an area-preserving form of the spectra.

characteristics, especially for small vertical scale components. Although this particular case study in Fig. 3 indicated that the shortest wavelengths that can be captured with FSI is as short as $200 \mathrm{~m}$, we limited the minimum wavelength to $500 \mathrm{~m}$ in this study, following the statistical study by Tsuda et al. (2011).

The main focus of this research was the climatological characteristics of the vertical wavenumber spectra of the GWs. We averaged the vertical wavenumber spectra every $5^{\circ}$ in latitude in both longitude regions, (a) and (b). We calculated the integrated (potential) energy from the analyzed spectra in the entire wavenumber range from $2.9 \times 10^{-4}$ to $2 \times 10^{-3} \mathrm{cyc} \mathrm{m}^{-1}$ (3.5 to $0.5 \mathrm{~km}$ in wavelength), which is defined as the total potential energy, $E_{\mathrm{p}}^{\mathrm{T}}$. Note that the first point in a spectrum was neglected, since it is largely affected by the Hanning window function. A part of the wave energy for large wavenumber range from $5.7 \times 10^{-4}$ to $2 \times 10^{-3}$ cyc m$^{-1}(1.75$ to $0.5 \mathrm{~km})$ was also calculated and this value was defined as $E_{\mathrm{p}}^{\mathrm{S}}$, which was unable to be investigated in earlier studies through the use of the GO profiles. Using these values, we calculated percentage of the potential energy, $E_{\mathrm{p}} \%=E_{\mathrm{p}}^{\mathrm{S}} / E_{\mathrm{p}}^{\mathrm{T}} \times 100$, for small-scale $\mathrm{GWs}$ (wavelengths from 0.5 to $1.75 \mathrm{~km}$ ). The spectral slope, $p$, is defined as linear regression from logarithmic plot of power spectral density of normalized temperature fluctuations. We estimated $p$ for a wavenumber range from $5.7 \times 10^{-4}$ to $2 \times 10^{-3}$ cyc m$^{-1}$.
In order to discuss the relationship of the GW activity with the background mean winds, $U$, we used monthly mean $U$ from NCEP reanalysis data provided by the NOAA Earth System Research Laboratory. We also refer to the satellite data of outgoing longwave radiation (OLR) as a proxy of the tropical convection at low latitudes.

We aim at showing a statistical result on the distribution of GW energy using vertical wavenumber spectra. As pointed out by Šácha et al. (2015) and elsewhere, it is noteworthy, however, that the wave potential energy may not be a conserved physical value when it is estimated by integrating the wave variance in a selected wavelength range. The vertical wavenumber of GWs varies depending on the background wind shear conditions. For the studies on the effects of wave dissipation on the general circulation, the upward flux of horizontal momentum associated with GWs should be accurately estimated. However, this measurement is rather difficult, except for when it is studied by means of a large atmospheric radar, such as the MU radar (e.g. Tusda et al., 1991).

\section{Results and discussion}

\subsection{Distribution of Brunt-Väisälä frequency squared, $N^{2}$}

We investigated variations in the Brunt-Väisälä frequency squared, $N^{2}$, because the spectral density in Eq. (1) depends on the background value of $N^{2}$. We analyzed $N^{2}$ using COSMIC GPS-RO temperature profiles, and found that $N^{2}$ is, in general, zonally homogenous. Therefore, we discuss latitude and seasonal variations in the monthly mean value of $N^{2}$ in $\operatorname{rad~s}^{-2}$ averaged at $20-27 \mathrm{~km}$ altitude. Figure 4 shows the results during 2007-2009 over longitude region (a). Similar results were also obtained over region (b) (not shown).

The top panel of Fig. 4 shows that $N^{2}$ in the polar region $\left(60-90^{\circ} \mathrm{S}\right)$ in the Southern Hemisphere (SH) exhibits a clear annual cycle. $N^{2}$ reached the maximum and minimum values of $6.5 \times 10^{-4}$ and $4 \times 10^{-4} \mathrm{rad} \mathrm{s}^{-2}$ in winter and summer, respectively. A seasonal variation was also evident at high latitudes $\left(50-90^{\circ} \mathrm{N}\right)$ in the $\mathrm{NH}$, but it exhibited considerable year-to-year differences probably due to sudden stratospheric warming events in winter of the $\mathrm{NH}$ (Harada et al., 2010). It is expected that the increase in $N^{2}$ could be related to an enhancement of GW energy in winter in the polar region, because the model spectrum indicates a proportionality of the spectral density with $N^{2}$ as in Eq. (1). In the 30-60 latitude regions in both the $\mathrm{NH}$ and $\mathrm{SH}$, seasonal changes in $N^{2}$ were not evident as compared to those at high latitudes.

We showed altitude versus latitude variations in $N^{2}$ in region (a) in the bottom panel of Fig. 4. A sharp increase in $N^{2}$ was clearly seen at around $15-17 \mathrm{~km}$ altitude in the latitude range from about $30^{\circ} \mathrm{S}$ to about $30^{\circ} \mathrm{N}$, clearly depicting a boundary between the troposphere and the stratosphere. The $N^{2}$ values were relatively stable at $20-27 \mathrm{~km}$ altitude at the 

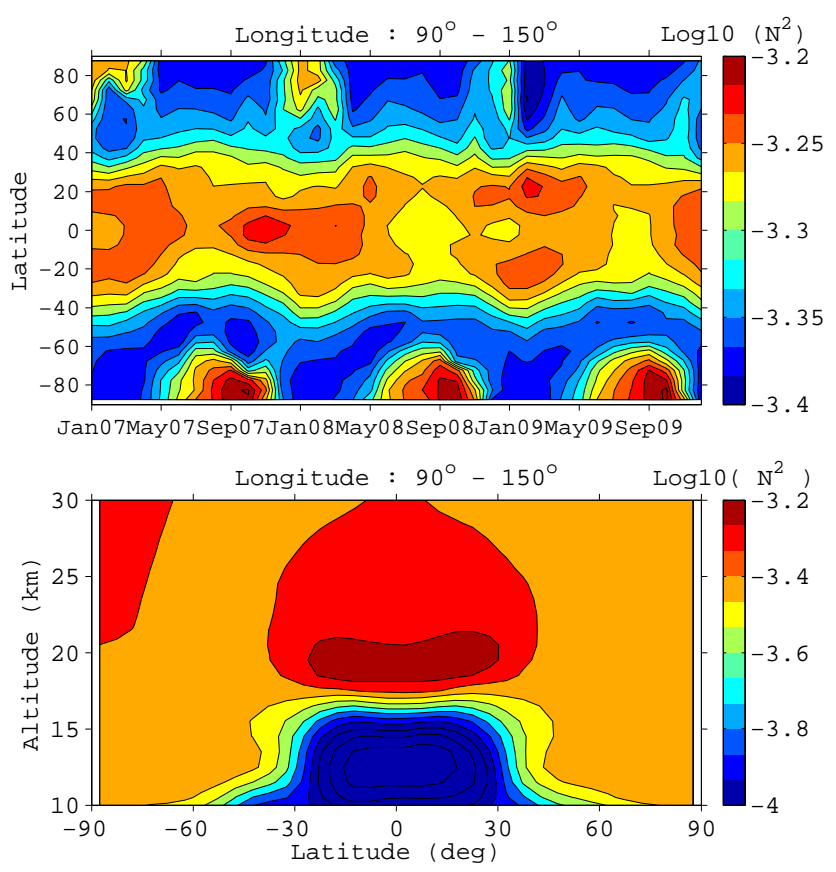

Figure 4. Top panel: latitude-time variation in Brunt-Väisälä frequency squared, $N^{2}$ in $\mathrm{rad} \mathrm{s}^{-2}$ averaged in the $20-27 \mathrm{~km}$ height range. The $N^{2}$ values are averaged every $5^{\circ}$ in latitude. Bottom panel: altitude-latitude variations in $N^{2}$ for a 3-year average.

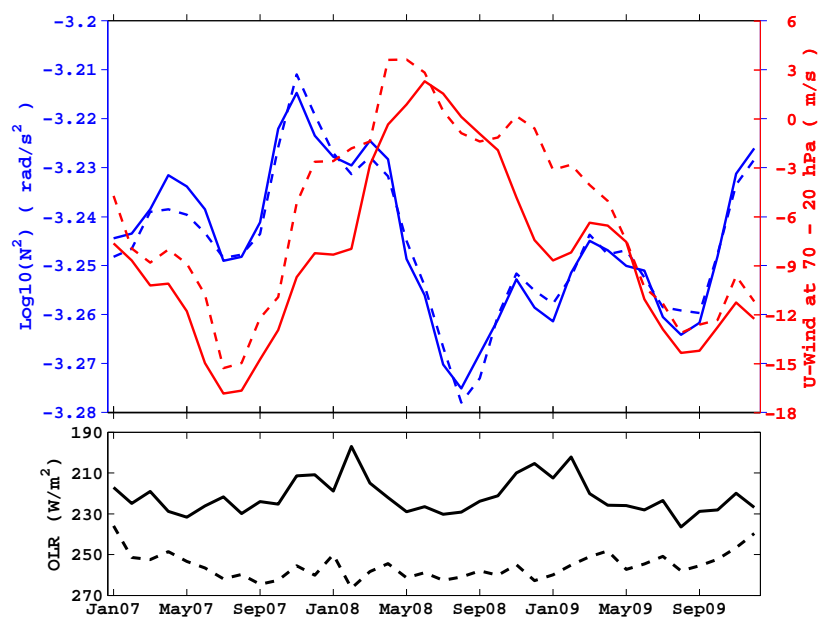

Figure 5. Time variations in $N^{2}$ (blue line) and $U$ (red line) with positive eastward propagation in the tropics in the $20-27 \mathrm{~km}$ height range (top panel) and OLR (bottom). Solid and dashed lines correspond to the longitude regions (a) $90-150^{\circ} \mathrm{E}$ and (b) $170-230^{\circ} \mathrm{E}$, respectively.

entire latitude range. Therefore, we decided to analyze the spectra in this height range.

Figure 5 shows the time series of mean $N^{2}$ and $U$ between latitudes $20^{\circ} \mathrm{S}$ and $20^{\circ} \mathrm{N}$ in the lower stratosphere $(20-27 \mathrm{~km})$. There are no significant differences in $N^{2}$ between longitude ranges (a) and (b), but $U$ shows slight differ-
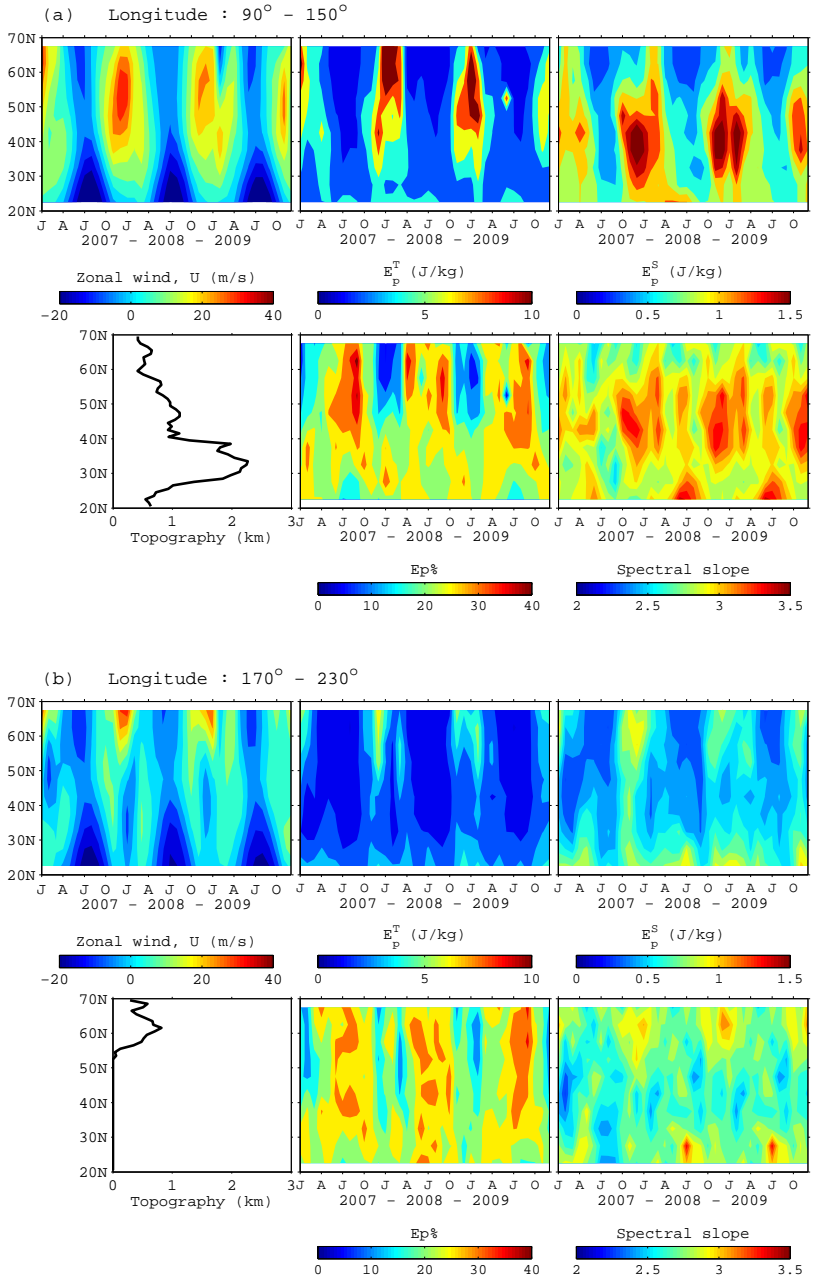

Figure 6. Latitude-time variations in GW parameters in the $\mathrm{NH}$ $\left(20-70^{\circ} \mathrm{N}\right)$ in longitude regions (a) and (b). In the top row in (a) and (b), panels are $U, E_{\mathrm{p}}^{\mathrm{T}}$, and $E_{\mathrm{p}}^{\mathrm{S}}$ from left to right. In the bottom row, the leftmost panel shows the mean of topography with $1^{\circ}$ latitude resolution averaged in the selected longitude regions, and the second and third panels are $E_{\mathrm{p}} \%$ and the absolute value of $p$, respectively.

ences between regions (a) and (b). Convective activity (OLR) in the bottom panel in Fig. 5 shows large differences between the (a) and (b). From November to February, small OLR values (active convection) were only described over region (a). $N^{2}$ in the equatorial region was affected by the QBO, as reported by Shimizu and Tsuda (2001) from long-term radiosonde observations. However, because the $N^{2}$ values here are averaged over a wide height range at $20-27 \mathrm{~km}$, it is difficult to clearly observe the effects of the QBO and convective activity on the variations in $N^{2}$.

\subsection{Latitude-time distribution of GW activity}

We investigated a latitude-time distribution of the monthly mean values of $E_{\mathrm{p}}^{\mathrm{T}}, E_{\mathrm{p}}^{\mathrm{S}}$ and $p$ and examined their rela- 


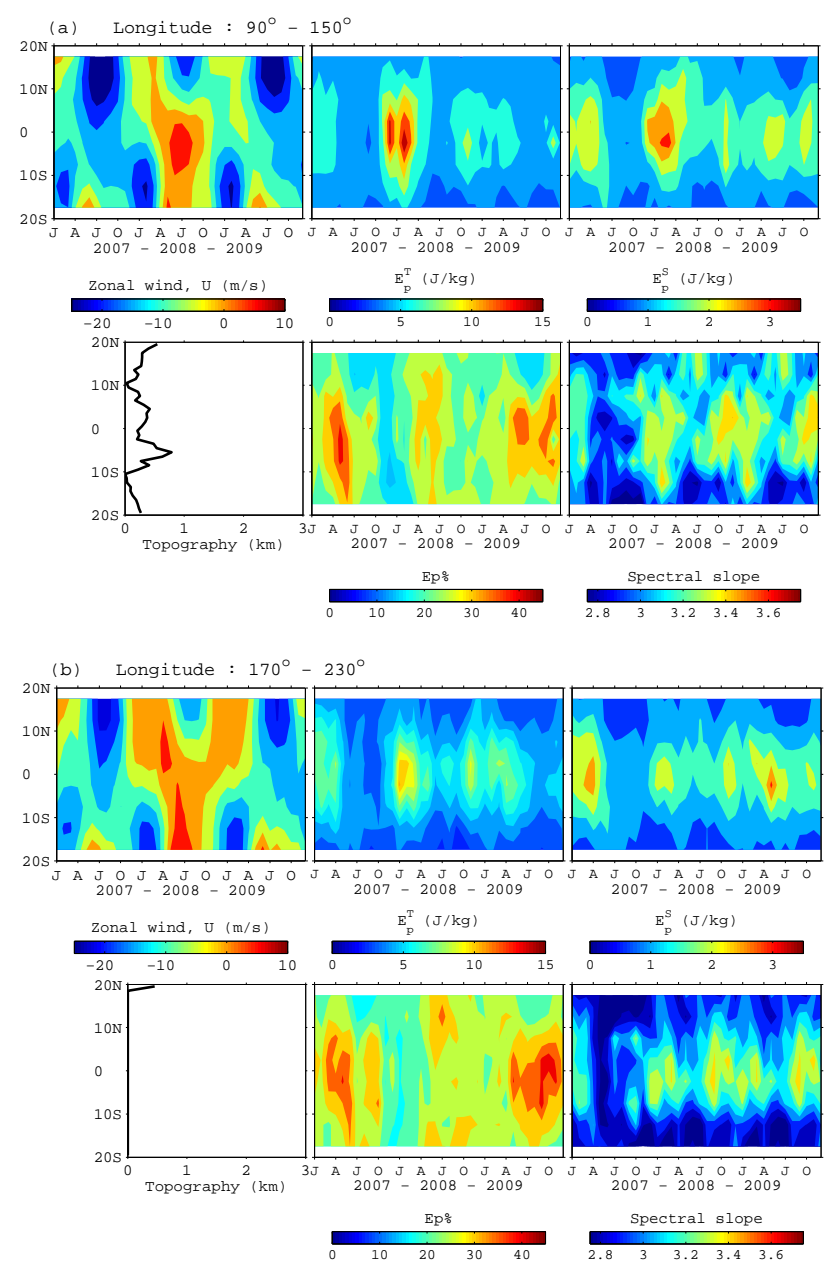

Figure 7. Same as Fig. 6 except in the tropics at $20^{\circ} \mathrm{S}-20^{\circ} \mathrm{N}$.

tion to topography and the background mean zonal wind velocity $(U)$ in the $70-20 \mathrm{hPa}$ level. Figures 6 , 7, and 8 show such distributions in three latitude ranges: $20-70^{\circ} \mathrm{N}$, $20^{\circ} \mathrm{S}-20^{\circ} \mathrm{N}$, and $20-70^{\circ} \mathrm{S}$, respectively. In Figs. 6-8, panels (a) and (b) show the result over two selected longitude regions (a) and (b) in Fig. 1, respectively. The mean topography in each longitude region is also plotted in Figs. 6-8. The values of $E_{\mathrm{p}}^{\mathrm{T}}, E_{\mathrm{p}}^{\mathrm{S}}, E_{\mathrm{p}} \%, p$, and $U$ were averaged in their respective longitude ranges. Since $p$ has a negative value, we plot the absolute magnitude of $p$.

Figure $6 \mathrm{a}$ and b show latitude-time variations in $E_{\mathrm{p}}^{\mathrm{T}}, E_{\mathrm{p}}^{\mathrm{S}}$, $E_{\mathrm{p}} \%$, and the absolute values of $p$ and $U$ for the two longitude ranges (a) and (b), respectively. In Fig. 6a, $E_{\mathrm{p}}^{\mathrm{T}}$ clearly showed an annual cycle, having large $E_{\mathrm{p}}^{\mathrm{T}}$ in winter, which correlated with the evolution of $U$ at latitudes higher than $45^{\circ}$ N. $E_{\mathrm{p}}^{\mathrm{S}}$ had a good correlation with the eastward jet stream during December to February, although the wind strength at mid-latitudes in the $\mathrm{NH}$ was about $20 \mathrm{~m} \mathrm{~s}^{-1}$, which was weaker than at high latitudes (about $30-40 \mathrm{~m} \mathrm{~s}^{-1}$ ). The duration of the $E_{\mathrm{p}}^{\mathrm{S}}$ enhancement was longer than $E_{\mathrm{p}}^{\mathrm{T}}$; moreover,

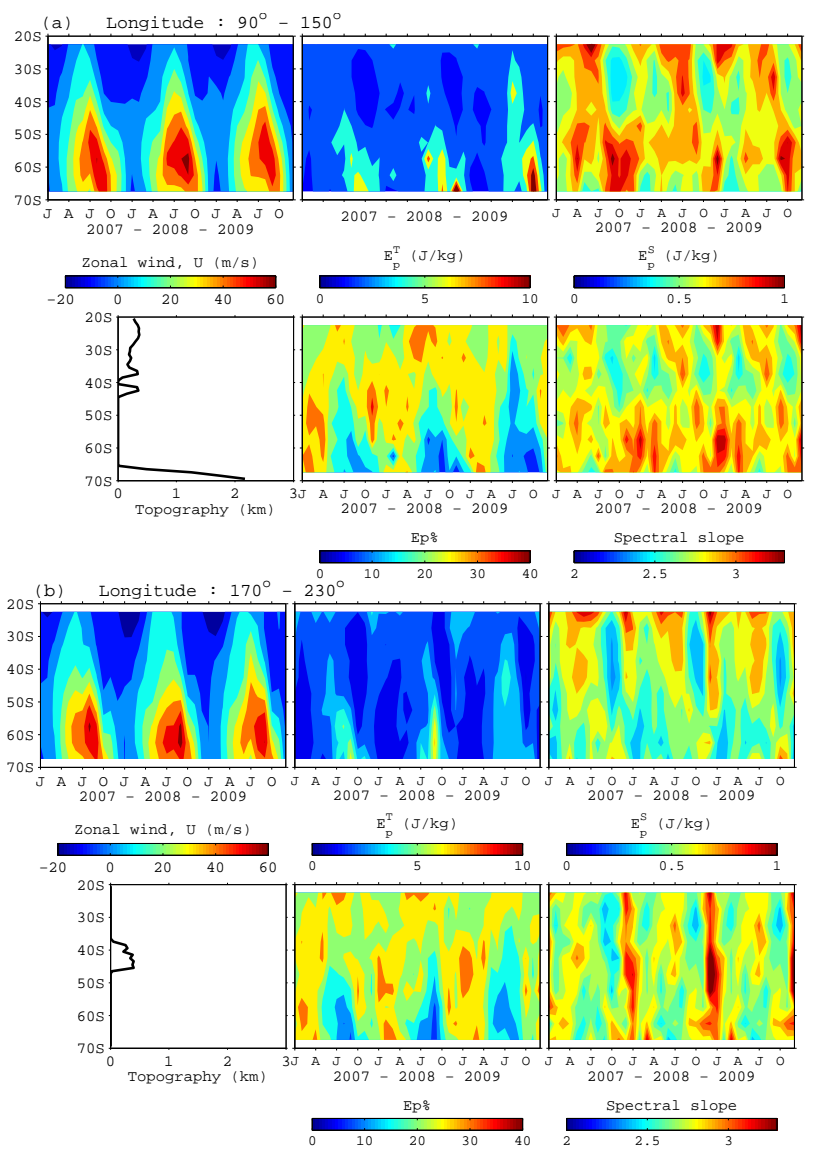

Figure 8. Same as Fig. 6 except in the $\mathrm{SH}$ at $20-70^{\circ} \mathrm{S}$.

the core of large $E_{\mathrm{p}}^{\mathrm{S}}$ occurred at lower latitudes at $25-40^{\circ} \mathrm{N}$. The distribution of $E_{\mathrm{p}}^{\mathrm{S}}$ seems to be considerably related to topography of the Tibetan Plateau, although the wave activity also coincided with $U$. On the other hand, $E_{\mathrm{p}}^{\mathrm{T}}$ is primarily affected by $U$.

Absolute $p$ values show an annual cycle ranging between 2.5 and 3.5. Distribution of $p$ is similar to $E_{\mathrm{p}}^{\mathrm{S}}$, having absolute $p$ values close to 3 in winter months at $30-55^{\circ} \mathrm{N}$. Note that the spectral slope became steeper than the model $(-3)$ in region (a) when $E_{\mathrm{p}}^{\mathrm{S}}$ was enhanced. On the other hand, absolute $p$ was as gradual as about 2.4 to 2.7 when $E_{\mathrm{p}}^{\mathrm{S}}$ was smaller. The magnitude of absolute $p$ over the ocean was smaller than that over land. Enhancement of $E_{\mathrm{p}}^{\mathrm{S}}$ indicated that more GWs with short vertical wavelengths are saturated, resulting in the absolute $p$ close to a theoretical value. Note that the large absolute $p$ below $30^{\circ} \mathrm{N}$ in summer (July) could be affected by GWs in the tropics.

In Fig. $6 \mathrm{~b}, E_{\mathrm{p}}^{\mathrm{T}}$ showed similar latitude-time variations like in region (a), showing a good correlation with $U$, but the magnitude of $E_{\mathrm{p}}^{\mathrm{T}}$ was in general about $60 \%$ of the values in region (a), indicating a contrast between the two longitude regions dominated by topography and ocean. In region (b), which has less topography except at $55-70^{\circ} \mathrm{N}, E_{\mathrm{p}}^{\mathrm{T}}$ was still 
related to the topography and the zonal winds $U . E_{\mathrm{p}}^{\mathrm{T}}$ at middle latitudes reached its maximum in December. The smaller $E_{\mathrm{p}}^{\mathrm{T}}$ over the ocean was related to the weakening of $U$. At $50-70^{\circ} \mathrm{N}$, where the Rocky Mountains lie, a larger GW energy was observed during the winter season due to poleward shift of jet streams. It is noteworthy that $U$ at $20-55^{\circ} \mathrm{N}$ in region (b) showed two enhancements, and these structures seemed to be reflected in $E_{\mathrm{p}}^{\mathrm{T}}$. Large $U$ occurred over topography, so it is difficult to distinguish its effects on $E_{\mathrm{p}}^{\mathrm{S}}$. The absolute $p$ became close to 3 when $E_{\mathrm{p}}^{\mathrm{S}}$ was larger.

In Fig. 6a and b, we plotted $E_{\mathrm{p}} \%$ in order to investigate relative contribution of $E_{\mathrm{p}}^{\mathrm{S}}$ to $E_{\mathrm{p}}^{\mathrm{T}}$. Large $E_{\mathrm{p}}^{\mathrm{T}}$ was concentrated in winter months and smaller in summer over all latitudes, while $E_{\mathrm{p}}^{\mathrm{S}}$ has a more extended distribution with season; therefore, the relative contribution of $E_{\mathrm{p}}^{\mathrm{S}}$ to the total GW activity was greater (about $30 \%$ ) in summer. This implies that long vertical scale GWs are mostly generated by the effects of the background mean zonal winds, while short vertical waves are excited by various mechanisms in addition to the background mean zonal wind.

These results are basically consistent with Alexander et al. (2008a). Note that $E_{\mathrm{p}}^{\mathrm{T}}$ tended to become larger at low latitudes below about $25^{\circ} \mathrm{N}$, which is more clearly recognized in region (b) (Fig. 6b). This distribution appears to be related to the large enhancement of $E_{\mathrm{p}}^{\mathrm{T}}$ in the tropics as explained later.

We show in Fig. 7 the distributions of GW parameters in the tropics which exhibited similar characteristics between region (a) over the Indonesian maritime continents and region (b) over the Pacific Ocean. The magnitude of $E_{\mathrm{p}}^{\mathrm{S}}$ was about one-third of $E_{\mathrm{p}}^{\mathrm{T}}$ and it depicted an annual cycle with the maximum from December to February. Larger $E_{\mathrm{p}}^{\mathrm{T}}$ was found in this period, coinciding with low OLR (tall clouds) in Fig. 5. Active convection during December to February seems to generate GWs, which then penetrate to higher altitudes, causing an increase in $E_{\mathrm{p}}^{\mathrm{T}}$. Alexander et al. (2008b) depicted the enhancement of GW energy from January to April in 2008, associated with low OLR and the beginning of the eastward phase of the QBO. However, the magnitude of $E_{\mathrm{p}}^{\mathrm{T}}$ was not always larger over region (a), where OLR values were generally much lower than in region (b), as seen in Fig. 5. In general, absolute $p$ was consistent with the model value of 3 , but it sometimes became 3.5. An annual cycle most clearly appeared in absolute $p$, showing steeper slope during convectively active periods. Further, a contrast in the absolute $p$ distribution between regions (a) and (b) was also recognized, showing a steeper slope in the former region, which could be related to the differences in cloud activity. The zonal winds $(U)$ showed characteristics of the QBO with some longitudinal differences between regions (a) and (b).

The above results suggest that cumulus cloud convection seems to have a significant effect on GWs. Although the analyzed periods are too short to clearly identify the effects of the $\mathrm{QBO}$ on $E_{\mathrm{p}}^{\mathrm{T}}$ and $E_{\mathrm{p}}^{\mathrm{S}}$, the QBO cycle seemed to appear in $E_{\mathrm{p}} \%$. That is, when the QBO was westward during July to October in $2008, E_{\mathrm{p}} \%$ was about $15 \%$, which is much smaller than in the same months in 2007 and 2009. $E_{\mathrm{p}} \%$ mostly ranged from 30 to $45 \%$ during the eastward phase of the QBO in 2007 and 2009. Note that $E_{\mathrm{p}} \%$ at middle latitudes in Fig. 6 was as large as $40 \%$, but in the tropics it sometimes exceeded $45 \%$.

Figure 8 shows results similar to Fig. 6 except in the SH. An annual cycle of $U$ was more prominent than in the $\mathrm{NH}$, having large $U$ during winter from April to October. $E_{\mathrm{p}}^{\mathrm{T}}$ in region (a) showed an annual cycle at $20-45^{\circ} \mathrm{S}$, coinciding with the westward winds of $U$. In addition, a secondary enhancement of $E_{\mathrm{p}}^{\mathrm{T}}$ seemed to appear at $20-25^{\circ} \mathrm{S}$ during DecemberFebruary, probably due to the effect of tropical convection.

Such seasonal variations were also seen in region (b). However, at $45-65^{\circ} \mathrm{S}$ in region (a), the annual cycle seen at low latitudes became unclear, indicating a gap at around $45^{\circ} \mathrm{S}$. However, in region (b), the seasonal cycle was extended smoothly down to about $55^{\circ} \mathrm{S}$. Thus, effects of topography (Australian continent) seem to be important in the $E_{\mathrm{p}}^{\mathrm{T}}$ variations in region (a). In the Antarctic region, $E_{\mathrm{p}}^{\mathrm{T}}$ became maximum in spring, showing a good correlation with the polar vortex (Yoshiki et al., 2004; Baumgaertner and McDonald, 2007; Hei et al., 2008; Sato et al., 2012). The differences in the magnitudes of $E_{\mathrm{p}}^{\mathrm{T}}$ between regions (a) and (b) could be attributed to the difference in topography.

The magnitude of $U$ showed a sharp decrease in October at high latitudes due to breakdown of the polar vortex. The core of $U$ existed at around $60^{\circ} \mathrm{S}$, and the weakening of $U$ started at low latitudes during July-August, and then it progressed toward the polar region. Such behavior of $U$ seems to be reflected in the time-latitude evolution of $\mathrm{GW}$ characteristics, which can be more clearly seen in $E_{\mathrm{p}}^{\mathrm{T}}$ and $p$. This interesting feature in the latitude-time variations in $\mathrm{GW}$ characteristics was most evident in $p$ in region (a).

\section{Comparison of seasonal cycles among different parameters}

We investigated the correlation between the latitude mean values of GW parameters and zonal winds using a time series of standard score ( $z$ score) defined below (Wu et al., 2001):

$z_{i}=\frac{x_{i}-\mu}{\sigma}$,

where $x_{i}$, which is supposed to have a Gaussian distribution, is the time series of a variable; $\mu$ and $\sigma$ are the mean and standard deviation of $x_{i}$, respectively. Figures 9 and 10 show $z$ scores of $E_{\mathrm{p}}^{\mathrm{T}}$ and $E_{\mathrm{p}}^{\mathrm{S}}$ as well as absolute values of $p$ and $U$ and the corresponding smoothed variation after applying a 3-month running mean. We tested and found that the GW parameters, in general, follow a Gaussian distribution. In particular, $\mu$ and $\sigma$ for absolute $p$ were about 2.7 and 0.14 , respectively. Therefore, a positive $z$ score for absolute $p$ indicates that the analyzed absolute $p$ is close to the model value 
(a)

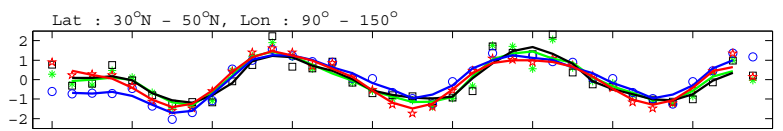

(b)

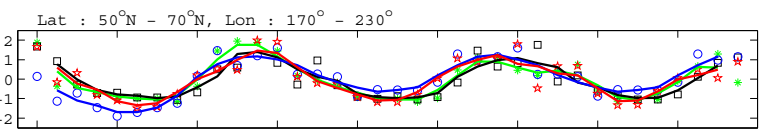

(c)

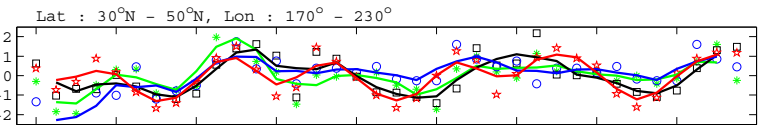

(d)

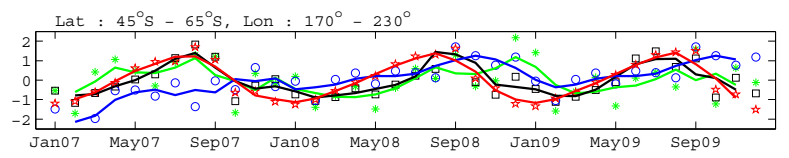

Figure 9. Monthly values of $z$ scores shown by squares, asterisks, stars, and circles for $E_{\mathrm{p}}^{\mathrm{T}}$ (black), $E_{\mathrm{p}}^{\mathrm{S}}$ (green), absolute of $p$ (blue), and $U$ (red), respectively, in the selected latitude and longitude ranges as shown on the top left of each panel. Smoothed lines are a 3 -month averaging. See text for more detail.
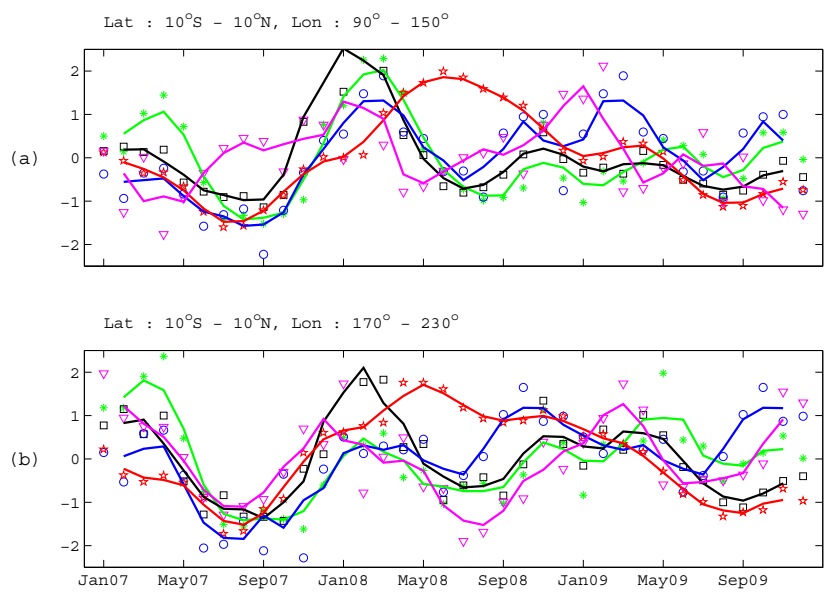

Figure 10. Same as Fig. 9 except for the equatorial region. The $z$ score of monthly mean of OLR were also plotted (triangle point and magenta line).

$(p=-3)$. A positive $z$ score for $U$ corresponds to the eastward winds.

In Fig. 9 we selected the latitude range $30-50^{\circ} \mathrm{N}$ in region (a) as plotted in panel (a). In region (b) the $z$ scores in the latitude ranges $30-50^{\circ} \mathrm{N}$ and $50-70^{\circ} \mathrm{N}$ are shown in panels (b) and (c) in order to examine the relationship between the GW parameters and the zonal winds by considering the difference in topography (see Fig. 1). We also show in panel (d) of Fig. 9 the $z$ scores at $45-65^{\circ} \mathrm{S}$ in region (b). Note that no significant topography exists for cases (c) and (d). In Fig. 10, we selected $10^{\circ} \mathrm{N}-10^{\circ} \mathrm{S}$ in regions (a) and (b), and we added the $z$ score for OLR data (note: the sign is reversed) to investigate the effects of convective activity.
In Fig. $9, E_{\mathrm{p}}^{\mathrm{T}}, E_{\mathrm{p}}^{\mathrm{S}}$, and $p$ are generally correlated well in all cases, particularly in panels (a) and (b). This indicates that when the GW activity was higher (larger $E_{\mathrm{p}}^{\mathrm{T}}$ ), the spectral slope became steeper (larger absolute $p$ ) approaching the saturated model spectrum. At $30-50^{\circ} \mathrm{N}$ in region (a) and 50 $70^{\circ} \mathrm{N}$ in region (b) in Fig. $9 \mathrm{a}$ and b, it is prominent that $E_{\mathrm{p}}^{\mathrm{T}}$, $E_{\mathrm{p}}^{\mathrm{S}}$, and $p$ are correlated very well with $U$. The $z$ scores show a clear annual oscillation with maximum and minimum during November-January and June-August, respectively. At $30-50^{\circ} \mathrm{N}$ in region (b) in Fig. 9c, an annual variation in $U$ was not dominant, but a semi-annual cycle was also recognized, and the amplitude of the mean wind velocity in Fig. 6 was weaker compared to other cases in Fig. 9a and b. However, $E_{\mathrm{p}}^{\mathrm{T}}, E_{\mathrm{p}}^{\mathrm{S}}$, and $p$ generally followed variations in $U$, although the correlation coefficient was smaller, such that it was about 0.48 and 0.35 for $U$ vs. $E_{\mathrm{p}}^{\mathrm{T}}$ and $U$ vs. $p$. These results suggest that GWs at the middle and high latitudes are mainly related to the background mean winds, and they seem to be reinforced by topography.

Figure 9d shows the $z$ scores in the SH in region (b) without significant topography. An annual cycle is seen in all parameters in Fig. 9d. Cross-correlation coefficients between $U$ vs. $E_{\mathrm{p}}^{\mathrm{T}}$ and $U$ vs. $p$ are 0.52 and 0.60 , respectively, and there was a time lag of about 2 months, which is different from the case in the NH shown in Fig. 9c. This time delay might be attributed to the latitudinal shift of $U$ toward the South Pole from the middle of year to the winter months.

In Fig. 10, an annual oscillation of $E_{\mathrm{p}}^{\mathrm{T}}$ is seen clearly in region (a), whereas $E_{\mathrm{p}}^{\mathrm{T}}$ was enhanced during the early years of 2007 and 2008, coinciding with the active phase of cumulus convection (see Fig. 5). The enhancement of $E_{\mathrm{p}}^{\mathrm{T}}$ is not clear in region (b), probably due to weaker convection. These results indicate that $\mathrm{GW}$ generation is related to the tropical convection. The $E_{\mathrm{p}}^{\mathrm{T}}$ decrease in January 2009 corresponds to the reversal of $U$, affected by a QBO phase (Randel and $\mathrm{Wu}$, 2005; Ryu and Lee, 2010).

\section{Latitudinal distribution of GW potential energy}

Figure 11 shows the ratio of $E_{\mathrm{p}}^{\mathrm{S}}$ to its theoretical value for the saturated GWs with wavelengths between 0.5 and $1.75 \mathrm{~km}$. The model GW energy was estimated by using the observed $N^{2}$. The ratio at $10^{\circ} \mathrm{S}-10^{\circ} \mathrm{N}$ latitude showed a steady enhancement, exceeding 1.0, regardless of season and longitude. The ratio at middle latitudes in the $\mathrm{NH}$ in region (a) was significantly enhanced in winter, being close to 1.0, suggesting the evident effects of topography in generating GWs by the Tibetan Plateau, located at around $30-50^{\circ} \mathrm{N}$ (Alexander et al., 2008a; Hei et al., 2008). At $50-80^{\circ} \mathrm{N}$ the ratio was about $0.6-0.75$ in winter, again indicating a relationship with topography (refer to Fig. 1). In winter, at $30-60^{\circ} \mathrm{S}$, the ratio was about 0.6, suggesting the effect of the topography of Australia and New Zealand in regions (a) and (b), respectively, and the ratio became as small as $0.4-0.5$ over $60^{\circ} \mathrm{S}$. 


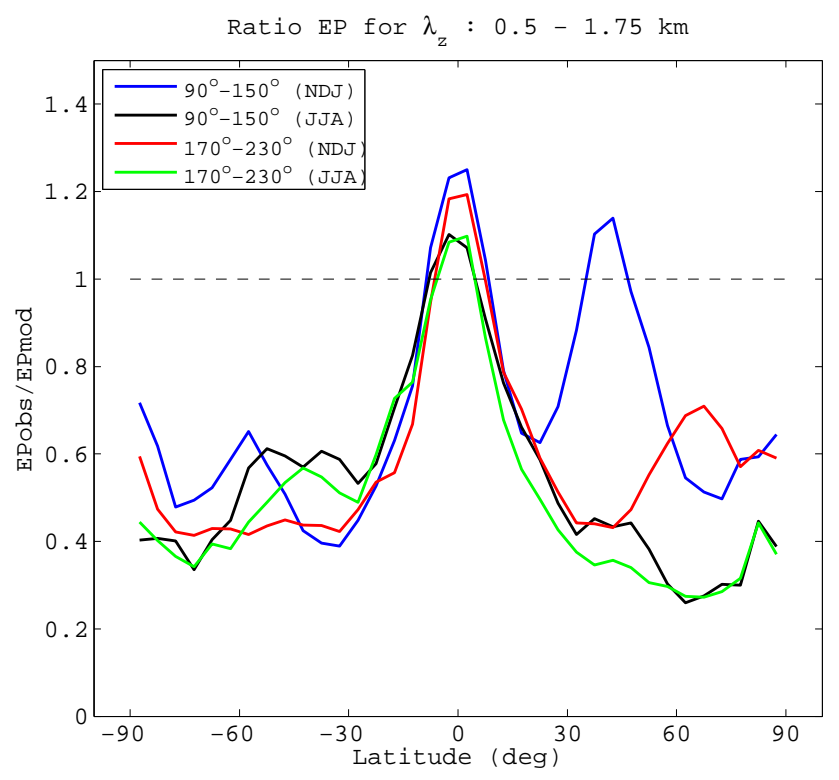

Figure 11. Ratio of the observed $E_{\mathrm{p}}^{\mathrm{S}}$ to the model value by saturated GW theory during November-December-January (NDJ, solid line) and June-July-August (JJA, dashed line). Blue and black lines correspond to the ratio in region (a). Red and green lines correspond to the ratio in region (b).

In summer, the ratio was as small as 0.3 at $50-70^{\circ} \mathrm{N}$ in both regions (a) and (b), while in the $\mathrm{SH}$ the ratio was slightly larger at about 0.4 at $40-60^{\circ} \mathrm{S}$, but only in region (b). In region (a) at $50-70^{\circ} \mathrm{S}$, the ratio became about $0.5-0.7$, because $E_{\mathrm{p}}^{\mathrm{S}}$ was still large in November as recognized in Fig. 8.

\section{Concluding remarks}

We analyzed the characteristics of GWs in the lower stratosphere using temperature profiles obtained with the COSMIC GPS-RO mission. We used high-vertical-resolution profiles retrieved by the FSI method over a period of 3 years from January 2007 to December 2009.

First, we examined the latitude-time variations in $N^{2}$ using GPS-RO profiles. The results indicated larger $N^{2}$ values in winter at high latitudes in the $\mathrm{NH}$ and the $\mathrm{SH}$, showing an annual oscillation. The variation in $N^{2}$ in the polar region of the $\mathrm{NH}$ was slightly different than that in the $\mathrm{SH}$, probably because of the effect of the sudden stratospheric warming in the $\mathrm{NH}$. Because the GW model spectral density is proportional to $N^{2}$, an increase in $N^{2}$ in the polar region could cause larger GW energy. The effects of the QBO and convective activity in variations in $N^{2}$ were not clear in the equatorial region, because the $N^{2}$ values were averaged over $20-27 \mathrm{~km}$ height range. We also investigated the heightlatitude distribution of $N^{2}$ at the longitude region $90-150^{\circ} \mathrm{E}$, then we selected the height range between 20 and $27 \mathrm{~km}$ for a spectral analysis, because $N^{2}$ did not vary greatly along the altitude over the entire latitude range. This height range is not influenced by sharp temperature variations near the tropical tropopause and the maximum height for a reliable FSI profile (Tsuda et al., 2011).

We analyzed vertical wavenumber spectrum of the normalized temperature perturbations, and calculated the wave potential energy $E_{\mathrm{p}}^{\mathrm{T}}$ and $E_{\mathrm{p}}^{\mathrm{S}}$ in the wavelengths ranges from 0.5 to $3.5 \mathrm{~km}$ and from 0.5 to $1.75 \mathrm{~km}$, respectively. We estimated the spectral slope $p$ in the wavelength range from 0.5 to $1.75 \mathrm{~km}$, where a model saturated spectrum can be compared. We also defined $E_{\mathrm{p}} \%$ as the percentage of $E_{\mathrm{p}}^{\mathrm{S}}$ contributed to the total potential energy $E_{\mathrm{p}}^{\mathrm{T}}$. We investigated latitude-time variations in these spectral parameters over two longitude regions: (a) $90-150^{\circ} \mathrm{E}$ and (b) $170-230^{\circ} \mathrm{E}$; topographical variations are larger in region (a), while oceans dominated region (b). We investigated the correlation between the spectral parameters with topography and the background mean zonal winds $(U)$ at three latitude ranges: $20-70^{\circ} \mathrm{N}$ in the $\mathrm{NH}$, $20^{\circ} \mathrm{N}-20^{\circ} \mathrm{S}$ in the tropics, and $20-70^{\circ} \mathrm{S}$ in the $\mathrm{SH}$.

In the $\mathrm{NH}, E_{\mathrm{p}}^{\mathrm{T}}$ and $E_{\mathrm{p}}^{\mathrm{S}}$ were clearly correlated with $U$ and topography, showing enhanced $E_{\mathrm{p}}^{\mathrm{T}}$ and $E_{\mathrm{p}}^{\mathrm{S}}$ in winter, and the magnitude of $E_{\mathrm{p}}^{\mathrm{T}}$ and $E_{\mathrm{p}}^{\mathrm{S}}$ was larger in region (a) than in region (b). We defined an annual variation in absolute $p$ in the $\mathrm{NH}$, being close to 3 in winter and ranging from 2.4 to 2.7 in summer. In both (a) and (b), absolute $p$ correlated well with $E_{\mathrm{p}}^{\mathrm{T}}$ and $E_{\mathrm{p}}^{\mathrm{S}}$. $U$ behaved differently in the SH than in the $\mathrm{NH}$, showing a latitudinal progression towards the polar regions (from 20 to $60^{\circ} \mathrm{S}$ ) from April to October. Meanwhile, the fluctuation of $E_{\mathrm{p}}^{\mathrm{T}}$ and $E_{\mathrm{p}}^{\mathrm{S}}$ was affected by cloud convection and related to the $\mathrm{QBO}$ zonal winds in the tropics. $E_{\mathrm{p}} \%$ was $26-40 \%$ in both the $\mathrm{NH}$ and the $\mathrm{SH}$ and $30-45 \%$ in the tropics.

We also examined the cross correlation of time variation in standard $z$ score value between $E_{\mathrm{p}}^{\mathrm{T}}, E_{\mathrm{p}}^{\mathrm{S}}, p$, and $U$. The $z$ scores of $U, E_{\mathrm{p}}^{\mathrm{T}}, E_{\mathrm{p}}^{\mathrm{S}}$, and $p$ correlated very well both at 30 50 and $50-70^{\circ} \mathrm{N}$ of regions (a) and (b), respectively, where topography exists. However, the $z$ scores at $30-50^{\circ} \mathrm{N}$ of region (b) showed an overlapped semi-annual oscillation. The ratio of $E_{\mathrm{p}}^{\mathrm{S}}$ with the saturated $\mathrm{GW}$ model spectrum was relatively stable in the $\mathrm{SH}$, ranging from 0.4 to 0.6 , but in the $\mathrm{NH}$ it showed large variations from 0.3 to 1.2 , depending on topography, and showed a clear contrast between winter and summer. In particular, the ratio exceeded 1.0 in winter at middle latitudes in the $\mathrm{NH}$ in region (a), indicating an important effect of topography. It is also noteworthy that the ratio of $E_{\mathrm{p}}^{\mathrm{S}}$ in the tropics was steadily large at 1.0-1.2 regardless of season and longitude. In particular, over the Equator the ratio was $1.2-1.3$ throughout a year.

We studied the vertical wavenumber spectra of saturated GWs using high-resolution COSMIC GPS RO data. These results show the superiority of the high vertical resolution of COSMIC GPS-RO derived using the FSI method. 
Acknowledgements. This work was supported by the JSPS KAKENHI (grant number 22253006). It was conducted as a part of the Global COE Program entitled "Sustainability/Survivability Science for a Resilient Society Adaptable to Extreme Weather Conditions" led by K. Takara. The first author (Noersomadi) is grateful to S. Yoden for providing travel support to Noersomadi from the Asia-Africa Science Platform of JSPS Core-to-Core Program, entitled "International Research Collaborations and Networking on Extreme Weather in Changing Climate in the Maritime Continent". This study was also supported by the Future Development Funding Program of Kyoto University Research Coordination Alliance. The authors appreciate the continuous support by the staff of the LAPAN. They also thank the COSMIC Data Analysis and Archive Center (CDAAC) for the GPS-RO data, and the Physical Sciences Division of the Earth System Research Laboratory for the NOAA reanalysis zonal wind and OLR data set. The authors would like to thank D. Riggin for helpful suggestions.

The topical editor, C. Jacobi, thanks two anonymous referees for help in evaluating this paper.

\section{References}

Alexander, M. J. and Holton, J. R.: A model study of zonal forcing in the equatorial stratosphere by convectively induced gravity waves, J. Atmos. Sci., 54, 408-419, 1997.

Alexander, M. J., Tsuda, T., and Vincent, R. A.: Latitudinal variations observed in GWs with short $\lambda \mathrm{s}$, J. Atmos. Sci., 59, 13941404, 2002.

Alexander, M. J., Geller, M., McLandress, C., Polavarapu, S., Preusse, P., Sassi, F., Sato, K., Eckermann, S., Ern, M., Hertzog, A., Kawatani, Y., Pulido, M., Shaw, T., Sigmond, M., Vincent, R., and Watanabe, S.: Recent developments in gravity-wave effects in climate models and the global distribution of gravitywave momentum flux from observation and models, Q. J. Roy. Meteor. Soc., 136, 1103-1124, doi:10.1002/qj.637, 2010.

Alexander, S. P., Tsuda, T., and Kawatani, Y.: COSMIC GPS observations of northern hemisphere winter stratospheric GWs and comparisons with an atmospheric general circulation model, Geophys. Res. Lett., 35, L10808, doi:10.1029/2008GL033174, 2008a.

Alexander, S. P., Tsuda, T., Kawatani, Y., and Takahashi, M.: Global distribution of atmospheric waves in the equatorial upper troposphere and lower stratosphere region: 1. COSMIC observations of wave mean flow interactions, J. Geophys. Res., 113, 1-18, doi:10.1029/2008JD010039, 2008b.

Alexander, S. P., Klekociuk, A. R., and Murphy, D. J.: Rayleigh lidar observations of gravity wave activity in the winter upper stratosphere and lower mesosphere above Davis, Antarctica $\left(69^{\circ} \mathrm{S}, 78^{\circ} \mathrm{E}\right)$, J. Geophys. Res., 116, 1-12, doi:10.1029/2010JD015164, 2011.

Baumgaertner, A. J. G. and McDonald, A. J.: A GW climatology for Antarctica compiled from Challenging Minisatellite Payload/Global Positioning System (CHAMP/GPS) radio occultations, J. Geophys. Res., 112, D05103, doi:10.1029/2006JD007504, 2007.

de la Torre, A. and Alexander, P.: GWs above Andes detected from GPS radio occultation temperature profiles: Mountain forcing?,
Geophys. Res. Lett., 32, L17815, doi:10.1029/2005GL022959, 2005.

Eckermann, S. D.: Effect of Background Winds on Vertical Wavenumber spectra of atmospheric GWs, J. Geophys. Res., 100, 14097-14112, 1995.

Eckermann, S. D., Hirota, I., and Hocking, W. K.: GW and equatorial wave morphology of the stratosphere derived from long-term rocket soundings, Q. J. Roy. Meteor. Soc., 121, 149-186, 1995.

Fritts, D. C.: A Review of GW Saturation Process, Effects, and Variability in the Middle Atmosphere, Pageoph., 130, 343-371, 1989.

Fritts, D. C. and Alexander, M. J.: GW dynamics and effects in the middle atmosphere, Rev. Geophys., 41, 1003, doi:10.1029/2001RG000106, 2003.

Fritts, D. C. and Chou, H. G.: An investigation of the vertical wavenumber and frequency spectra of gravity wave motions in the lower stratosphere, J. Atmos. Sci., 44, 3610-3624, 1987.

Fritts, D. C., Tsuda, T., Sato, T., Fukao, S., and Kato, S.: Observational evidence of a saturated gravity wave spectrum in the troposphere and lower stratosphere, J. Atmos. Sci., 45, 1741-1759, 1988.

Harada, Y., Goto, A., Hasegawa, H., Fujikawa, N., Naoe, H., and Hirooka, T.: A Major stratospheric sudden warming event in January 2009, J. Atmos. Sci., 67, 2052-2060, 2010.

Hei, H., Tsuda, T., and Hirooka, T.: Characteristics of atmospheric GW activity in the polar regions revealed by GPS radio occultation data with CHAMP, J. Geophys. Res., 113, D04107, doi:10.1029/2007JD008938, 2008.

Jensen, A. S., Lohmann, M. S., Benzon, H.-H., and Nielsen, A. S.: Full Spectrum Inversion of radio occultation signals, Radio Sci., 38, 6-1-6-15, doi:10.1029/2002RS002763, 2003.

Jiang, J. H., Eckermann, S. D., Wu, D. L., Hocke, K., Wang, B., Ma, J., and Zhang, Y.: Seasonal variation of GW sources from satellite observation, Elsevier Ltd., 35, 1925-1932, 2005.

Kawatani, Y., Takahashi, M., Sato, K., Alexander, S. P., and Tsuda, T.: Global distribution of atmospheric waves in the equatorial upper troposphere and lower stratosphere: AGCM simulation of sources and propagation, J. Geophys. Res., 114, 1-23, doi:10.1029/2008JD010374, 2009.

Kuo, Y. H., Sokolovskiy, S., Rocken, C., Schreiner, W., Hunt, D., and Anthes, R. A.: Inversion and Error Estimation of GPS Radio Occultation Data, J. Meteorol. Soc. Jpn., 82, 507-531, 2004.

Kursinski, E. R., Hajj, G. A., Schofield, J. T., Linfield, R. P., and Hardy, K. R.: Observing Earth's atmosphere with radio occultation measurements using Global Positioning System, J. Geophys. Res., 102, 23429-23465, 1997.

Lindzen, R. S.: Turbulence and stress owing to gravity wave and tidal breakdown, J. Geophys. Res., 86, 9707-9714, 1981.

Marquardt, C. and Healy, S. B.: Notes and correspondence measurement noise and stratospheric gravity wave characteristics obtained from GPS occultation data, J. Meteorol. Soc. Jpn., 83, 417428, 2005.

Murayama, Y., Tsuda, T., and Fukao, S.: Seasonal variation of gravity wave activity in the lower atmosphere observed with the MU radar, J. Geoph. Res., 99, 23057-23069, 1994.

Narendra Babu, A., Kishore Kumar, K., Kishore Kumar, G., Venkat Ratnam, M., Vijaya Bhaskara Rao, S., and Narayana Rao, D.: Long-term MST radar observations of vertical wave number spectra of gravity waves in the tropical troposphere over Gadanki 
$\left(13.5^{\circ} \mathrm{N}, 79.2^{\circ} \mathrm{E}\right)$ : comparison with model spectra, Ann. Geophys., 26, 1671-1680, doi:10.5194/angeo-26-1671-2008, 2008.

Randel, W. J. and Wu, F.: Kelvin wave variability near the equatorial tropopause observed in GPS radio occultation measurements, J. Geophys. Res., 110, D03102, doi:10.1029/2004JD005006, 2005.

Ratnam, M. V., Tsuda, T., Jacobi, C., and Aoyama, Y.: Enhancement of gravity wave activity observed during a major Southern Hemisphere stratospheric warmings by CHAMP/GPS measurement, Geophys. Res. Lett., 31, L16101, doi:10.1029/2004GL019789, 2004.

Rocken, C., Anthes, R., Exner, M., Hunt, D., Sokolovsky, S., Ware, R., Gourbunov, M., Schreiner, W., Feng, D., Herman, B., Kuo, Y.-H., and Zou, X.: Analysis and validation of GPS/MET data in the neutral atmosphere, J. Geophys. Res., 102, 29849-29866, 1997.

Ryu, J. H. and Lee, S.: Effect of Tropical Waves on the Tropical Tropopause Transition Layer Upwelling, J. Atmos. Sci., 67, 3130-3148, 2010.

Šácha, P., Foelsche, U., and Pišoft, P.: Analysis of internal gravity waves with GPS RO density profiles, Atmos. Meas. Tech., 7, 4123-4132, doi:10.5194/amt-7-4123-2014, 2014.

Šácha, P., Kuchar, A., Jacobi, C., and Pišoft, P.: Enhanced internal gravity wave activity and breaking over the northeastern Pacificeastern Asian region, Atmos. Chem. Phys., 15, 13097-13112, doi:10.5194/acp-15-13097-2015, 2015.

Sato, K. and Yoshiki, M.: Gravity wave generation around the polar vortex in the stratosphere revealed by 3-hourly radiosonde observations at Syowa Station, J. Atmos. Sci., 65, 3719-3735, doi:10.1175/2008JAS2539.1, 2008.

Sato, K., Tateno, S., Watanabe, S., and Kawatani, Y.: GWs Characteristics in the Southern Hemisphere Revealed by a HighResolution Middle Atmosphere General Circulation Model, J. Atmos. Sci., 69, 1378-1395, 2012.

Shimizu, A. and Tsuda, T.: Seasonal and QBO-related Variations in GW Activities Observed with Radiosonde at Bandung Indonesia, J. Meteorol. Soc. Jpn., 79, 185-200, 2001.

Smith, S. A., Fritts, D. C., and VanZandt, T. E.: Evidence for a Saturated Spectrum of Atmospheric GWs, J. Atmos. Sci., 44, 1404 1410, 1987.

Tsuda, T.: Characteristics of atmospheric gravity waves observed using the MU (Middle and Upper atmosphere) radar and GPS (Global Positioning System) radio occultation, P. Jpn. Acad. BPhys., 90, 12-27, 2014.

Tsuda, T. and Hocke, K.: Vertical Wave Number Spectrum of Temperature Fluctuations in the Stratosphere using GPS Occultation Data, J. Meteorol. Soc. Jpn., 80, 925-938, 2002.

Tsuda, T., Inoue, T., Fritts, D. C., VanZandt, T. E., Kato, S., Sato, T., and Fukao, S.: MST radar observations of a saturated gravity wave spectrum, J. Atmos. Sci., 46, 2440-2447, 1989.
Tsuda, T., Murayama, Y., Yamamoto, M., Kato, S., and Fukao, S.: Seasonal variation of momentum flux in the mesosphere observed with the MU radar, Geophys. Res. Lett., 17, 725-728, 1990.

Tsuda, T., VanZandt, T.E., Mizumoto, M., Kato, S., and Fukao, S.: Spectral Analysis of Temperature and Brunt-Vaisala Frequency Fluctuations Observed by Radiosondes, J. Geophys. Res., 96, 17265-17278, doi:10/1029.91JD01944, 1991.

Tsuda, T., Nishida, M., Rocken, C., and Ware, R. H.: A global morphology of GW activity in the stratosphere revealed by the GPS occultation data (GPS/MET), J. Geophys. Res., 105, 7257-7273, 2000.

Tsuda, T., Ratnam, M. V., Alexander, S. P., Kozu, T., and Takayabu, Y.: Temporal and spatial distributions of atmospheric wave energy in the equatorial stratosphere revealed by GPS radio occultation temperature data obtained with the CHAMP Satellite during 2001-2006, Earth Planets Space, 61, 525-533, 2009.

Tsuda, T., Lin, X., Hayashi, H., and Noersomadi: Analysis of vertical wave number spectrum of atmospheric gravity waves in the stratosphere using COSMIC GPS radio occultation data, Atmos. Meas. Tech., 4, 1627-1636, doi:10.5194/amt-4-1627-2011, 2011.

VanZandt, T. E.: A universal spectrum of buoyancy waves in the atmosphere, Geophys. Res. Lett., 9, 575-578, 1982.

Wu, D. L.: Small-scale fluctuations and scintillations in highresolution GPS/CHAMP SNR and phase data, JASTP, 68, 9991017, 2006.

Wu, D. L. and Waters, J. W.: Satellite observations of atmospheric variances: A possible indication of gravity wave, Geophys. Res. Lett., 23, 3631-3634, 1996.

Wu, H., Hayes, M. J., Weiss, A., and Hu, Q.: An Evaluation of the Standardized Precipitation Index, the-China-Z Index and the Statistical Z-score, Int. J. Climatol., 21, 745-758, 2001.

Wu, Y., Xu, J., Yuan, W., Chen, H., and Bian, J.: Spectral analysis of $10-\mathrm{m}$ resolution temperature profiles from balloon soundings over Beijing, Ann. Geophys., 24, 1801-1808, doi:10.5194/angeo-24-1801-2006, 2006.

Yamashita, C., Chu, X., Liu, H. L., Espy, P. J., Nott, G. J., and Huang, W.: Stratospheric gravity wave characteristics and seasonal variations observed by lidar at the South Pole and Rothera, Antarctica, J. Geophys. Res., 114, 1-11, doi:10.1029/2008JD011472, 2009.

Yoshiki, M., Kizu, N., and Sato, K.: Energy enhancements of gravity waves in the Antarctic lower stratosphere associated with variations in the polar vortex and tropospheric disturbances, J. Geophys. Res., 109, D23104, doi:10.1029/2004JD004870, 2004.

Zhang, S. D., Huang, C., and Yi, F.: Radiosonde observations of vertical wave number spectra for gravity waves in the lower atmosphere over Central China, Ann. Geophys., 24, 3257-3265, doi:10.5194/angeo-24-3257-2006, 2006. 